\title{
Memórias como fonte de pesquisa em história e antropologia
}

\author{
Anamaria Marcon Venson* \\ Joana Maria Pedro**
}

Memória e identidade são categorias centrais nas teorias das ciências humanas e são operacionalizadas em reflexões de diferentes áreas e campos disciplinares. Hoje, parece que se organiza o esboço de um consenso em torno da noção de que o lugar da memória é aquele da produção de subjetividades, da construção de identificações. A entrevista, uma chamada para a significação da experiência, é ferramenta e fonte tanto da história quanto da antropologia, disciplinas essas que articulam metodologias particulares amparando-se nos estudos sobre a memória, em análises de narrativas, na interpretação daquilo que é lembrado e esquecido, nos contraditos e nas repetições, na elaboração de significados, nos modos de dizer.

Nossa proposta neste ensaio é um breve relato das teorias da memória que constituem o arsenal teórico desses dois campos de saber que há muito dialogam: história e antropologia. Especificamente, pretendemos refletir sobre a colocação em discurso da categoria memória por essas duas áreas disciplinares, seus usos e apropriações, seus jogos com as categorias identidade e subjetividade. Pretendemos tratar essas abordagens como discursividades que

* Doutoranda no Programa de Pós-Graduação Interdisciplinar em Ciências Humanas (PPGICH) e pesquisadora do Laboratório de Estudos de Gênero e História, na Universidade Federal de Santa Catarina (UFSC). Bolsista Capes.

** Professora do Programa de Pós-Graduação Interdisciplinar em Ciências Humanas (PPGICH) e do Programa de Pós-Graduação em História, na Universidade Federal de Santa Catarina (UFSC) e pesquisadora do Laboratório de Estudos de Gênero e História - UFSC. 
se complementam e se emprestam uma à outra, que encontram uma na outra apoio e condição, mas que são perspectivadas de diferentes lugares de saber.

Primeiramente, colocamos em evidência o tratamento epistemológico que estamos dispensando nessa nossa leitura acerca da operacionalização da categoria memória. Depois, tentamos elaborar, resumidamente, um percurso das disciplinas antropologia e história para mostrar como elas foram se configurando no século XX em torno de preocupações comuns. Se a entrevista é uma técnica de produção de fonte nas duas disciplinas, escrevemos numa tentativa de arranjar uma maneira de tratar as fontes orais informadas por esses dois campos de saber. Em seguida, fazemos algumas observações sobre o que se convencionou chamar história oral e etnografia da memória. Finalizamos com breves considerações acerca das articulações entre as categorias memória, subjetividade e identificação, mostrando como a categoria gênero, elaborada dentro dos estudos feministas, propiciou novas teorias da sujeita ${ }^{1} \mathrm{e}$ trouxe ao debate novas problemáticas acerca do tratamento dado à memória.

Para problematizar como a memória é utilizada como categoria nestes dois campos de saber, história e antropologia, preferimos utilizar o arsenal teórico foucaultiano, que sugere a investigação dos discursos que deram visibilidade e que tornaram dizível certa prática. Discurso, aqui, tem um sentido técnico particular. Não significa o que é dito (Veyne, 1982). Discurso, aqui, é entendido como prática, pois é a prática que determina os objetos, e não o contrário; e só existe o que é determinado, afinal, as coisas não existem fora das práticas (Foucault, 1996). Portanto, aquilo que entendemos como memória, e o próprio uso da memória como fonte de um conhecimento produzido, são práticas datadas e dimensionadas por relações de poder. Estamos entendendo relações de poder também como aparecem em Foucault: instáveis e possíveis de reversibilidade, disputas, embates, jogos estratégicos pelos quais pessoas livres procuram se conduzir e determinar a conduta das outras (Foucault, 1988, 2003). O ato de rememorar se configura dentro de uma

1 A utilização dos substantivos flexionados no gênero feminino, no decorrer do texto, é uma escolha política. Fazemos isso para chamar atenção ao fato de que quando se pretende o neutro, se utiliza o masculino. A pretensa neutralidade, portanto, tem gênero: o masculino. Sempre que não for possível utilizar um substantivo sobrecomum (de gênero invariável), utilizaremos substantivos e demais classes gramaticais devidamente flexionadas no feminino para designar a coletividade e para conceitos filosóficos. Aqueles e, porventura, aquelas que não concordam com esta opção, esperamos que reconheçam o fato de que somos duas autoras mulheres e estamos fazendo um exercício de nos incluir na linguagem que nós próprias produzimos. 
relação de poder. Tanto em função da relação entre a pessoa que pergunta e a pessoa que é perguntada quanto em função do tratamento que antropólogas e historiadoras decidem dar à memória. Nossos textos acadêmicos são produzidos no interior de disputas, de relações de poder, de redes de saber, e são estratégias; posicionamento esse que nos impede de tentar qualquer suspense em relação às considerações que nós mesmas temos tomado em relação à categoria que nos propusemos a problematizar: a memória é também um jogo discursivo e é um construto possível através de determinadas referências culturais.

Entendemos o ato de rememorar como um processo provocado pela proposta da pesquisadora e que é, em si, um modo de subjetivação. E estamos, uma vez mais, nos apropriando de Michel Foucault quando nos referimos a processos de produção de sujeitas e modos de subjetivação. Este autor iniciou sua produção acadêmica em meio ao movimento estruturalista, que entendia que as indivíduas são moldadas por estruturas sociológicas, psicológicas e linguísticas, sobre as quais não têm controle. Este filósofo, no entanto, tornou-se o mais importante representante do movimento pós-estruturalista, que junto com o desconstrucionismo proposto por Jacques Derrida compuseram o que se convencionou chamar pós-modernismo. Pós-modernistas não concordam que haja uma verdade para ser descoberta ou uma maneira de obter respostas verdadeiras/objetivas para as questóes em torno da condição humana, pois entendem a razão como uma forma particular e histórica de explicar o mundo.

Embora os primeiros trabalhos de Foucault não tivessem como foco a subjetividade, eles permitiram o desenvolvimento de uma crítica a essa noção. ${ }^{2}$ Seu "método arqueológico" permitiu que historiadoras das ideias descentrassem suas análises da primazia da indivídua/sujeita na historiografia tradicional. E o "método genealógico" serviria para explicar as transições de um modo de pensar para outro, sugerindo, inspirado em Nietzsche, uma ideia de origem como algo complexo, em contraste à noção de um esquema de história progressiva. ${ }^{3}$ Se este filósofo se preocupou em analisar

2 Nos referimos a $O$ nascimento da clinica (Foucault, 1980), As palavras e as coisas (Foucault, 1995) e A arqueologia do saber (Foucault, 1986a), originalmente publicados em 1963, 1966 e 1969, respectivamente.

3 Método genealógico desenvolvido em Vigiar e punir (Foucault, 1986b), originalmente publicado em 1975 . 
como as sujeitas são produzidas por relações de poder e saber, e não dados em essência, mas são objetos de disciplinamento, ele pensou também numa outra dimensão do poder associado às ciências da sexualidade. $\mathrm{O}$ controle não seria exercido somente através do conhecimento dos outros sobre uma indivídua, mas também através da indivídua sobre si mesma. Foucault argumentou que as indivíduas internalizam as normas colocadas pela ciência da sexualidade e produzem a si mesmas num esforço para conformar-se a essas normas. Desse modo, indivíduas não são somente objetos de disciplinas, mas também sujeitas. Assim ele criou e cunhou o conceito filosófico original de modos de subjetivação. ${ }^{4}$

Através de quais jogos de verdade o ser humano se reconheceu como ser de desejo? Foucault parte dessa pergunta para analisar práticas pelas quais as indivíduas foram levadas a prestar atenção a si próprias, a se decifrar, a se reconhecer e se confessar como sujeitas de desejo, estabelecendo de si para consigo uma certa relação que lhes permite descobrir, no desejo, a verdade do seu ser. Está, aí, bem colocada a diferenciação entre interdição e problematização moral. Este filósofo estudou como as sujeitas decodificam as normas e produzem a si mesmas, como se relacionam com a verdade no processo de constituição de si. E preocupou-se, portanto, em pensar como os modos de subjetivação se fazem fora das malhas de poder, buscar a formação do novo, a emergência, a invenção de novas possibilidades de vida.

E é nesse sentido que afirmamos que a memória é uma invenção. Não significa que estamos supondo que a pessoa que aceita arriscar respostas às nossas indagações de pesquisa esteja mentindo ou que esteja sendo levada pelo engano, mas que a rememoração é sempre um processo de subjetivação, de positivação, de refazer, de criação. Deleuze (1992) sugere que pensemos o conceito de "subjetivação" de Foucault no sentido de processo e o "si" no sentido de relação (relação a si), relação de força consigo, ao passo que o poder era uma relação de força com outras forças. A subjetivação é uma "dobra” da força, explica Deleuze. Dobrar a linha de força, constituir modos de existência capazes de resistir ao poder bem como de se furtar ao saber, mesmo se o saber tenta penetrá-los e o poder tenta apropriar-se deles, é assim que os modos de existência não cessam de se recriar e surgem novos (Deleuze, 1992). Desse

4 Desenvolvido na série "História da Sexualidade": A vontade de saber (Foucault, 1988), publicado na França em 1976, e $O$ uso dos prazeres (Foucault, 1984) e $O$ cuidado de si (Foucault, 1985), publicados na França em 1984. 
modo, resolvemos tratar a memória como uma discursividade, bem como o tratamento teórico dado a ela, e estamos tratando de discursos na perspectiva de Foucault: não como conjunto de signos remetido a um conteúdo ou a uma representação, mas como prática que forma os objetos dos quais fala (Foucault, 1986a).

Portanto, não é nossa intenção procurar nos processos de rememoração uma revelação e nem descobrir neles um fundamento, mas tomar as memórias como uma positividade, elas próprias como um acontecimento. E é tal acontecimento que nos interessa discutir. Não temos expectativas de que as memórias, construídas no jogo de perguntas e respostas como fontes de pesquisa, nos desvelem um real, pois que estamos persuadidas de que elas fabricam verdades e são mecanismos repletos de intenções e estratégias. A questão não é procurar a versão mais verdadeira, não é procurar nas fontes uma pista do que aconteceu na realidade, porque estamos entendendo que as memórias que pesquisamos, e que tratamos metodologicamente como discursos/práticas, são a realidade: elas dizem a sujeita que fala, produzem a sujeita falante, têm materialidade. Se discurso e prática são metodologicamente a mesma coisa, pois estamos entendendo que nada existe na forma pré-discursiva, não há um discurso anterior, uma metafísica que define o que aconteceu ou quem é a sujeita que rememora, afinal, estamos tratando o texto produzido no nosso encontro com a sujeita que nos fala como prática/discurso, como acontecimento.

A entrevista é uma técnica de chamada para a produção e a significação da memória, e esse entendimento é resultado de disputas metodológicas e colaboração, muitas vezes intencional, entre praticantes da história e da antropologia, praticantes essas que abriram para outros campos de saber a possibilidade de uma discussão acerca dos usos da oralidade na pesquisa. Atentas ao fato de que a questão epistemológica condiciona a investigação empírica, propomos mostrar como a categoria memória é colocada em discurso nas produções dessas duas disciplinas e tentar rascunhar uma possibilidade de tratamento interdisciplinar.

A tradição oral, a oralidade, é um objeto teórico constitutivo do arcabouço teórico da antropologia e é um meio de interpretação das culturas abordadas. A etnografia, metodologia descritiva e analítica utilizada por praticantes da antropologia cultural, se constitui de observação participante, que consiste em um método para elaborar um discurso sobre um grupo cultural, ou espaço particular, ou um problema social, possível pelo envolvimento da 
pesquisadora no universo proposto para a pesquisa, e de momentos de descrição e análise da experiência de observação, posicionando aquilo que foi interpretado dentro de um contexto cultural mais amplo. Clifford Geertz trata esses momentos como etapas da investigação: o being there (estar no campo) se articula com o being here (estar no contexto dos saberes universitários escrevendo sobre a experiência) (Geertz, 1988; Oliveira, 1995). A interpretação da experiência de observação é sempre balizada pelas categorias constitutivas da disciplina e controlada pela comunidade de pares. O trabalho etnográfico, que é feito com um olhar sensibilizado e instrumentalizado pela teoria, pode também incluir um roteiro de perguntas dirigidas às pessoas que compóem o grupo em estudo, que podem ser feitas tanto por meio de entrevistas formais quanto por conversas informais. A entrevista é, portanto, um ouvir especial, um encontro de idiomas culturais, um lugar compartilhado. Nas últimas décadas, estudos antropológicos têm transformado a modalidade "informante" em "interlocutora”, modalidade essa que leva em conta a noção de intersubjetividade.

A configuração tanto da antropologia cultural quanto da história como disciplina se deu no século XIX. James Frazer (1854-1941) é citado em muitos textos como o pai da antropologia moderna, mas foi com Franz Boas (1858-1942) que a proposta etnográfica tomou fôlego junto à oposição às perspectivas evolucionárias. Nos anos 1920, o afamado Bronislaw Malinowski propôs a observação participante como técnica e elaborou modelos e premissas de como fazer uma etnografia, enquanto Margaret Mead marcou o abandono da biologia e abriu espaço para explicações mais culturais. No pós-guerra, Claude Lévi-Strauss, lido por praticantes de várias áreas do conhecimento, se colocou como autor referência da abordagem estruturalista. Mas foi nos anos 1970, com a publicação em 1973 de A interpretação das culturas, por Clifford Geertz (1989), que historiadoras e historiadores incorporaram amplamente abordagens antropológicas em suas produções. Geertz, afinado com a discussão pós-estruturalista e, ao mesmo tempo, informando-a, propôs uma abordagem interpretativa ao mostrar as dificuldades da pesquisa etnográfica em conseguir uma descrição adequada/objetiva da realidade.

Também a história se estabeleceu como disciplina autônoma com pretensões científicas no século XIX. Aquele foi o tempo dos processos de consolidação dos Estados Nacionais, e alicerçar uma narrativa fidedigna que comprovasse e reforçasse os laços de identidade entre as habitantes das nações com base em uma presumida origem comum tornou-se uma questão 
para a história. Se as precursoras mais remotas do conhecimento histórico ocidental, como os gregos Heródoto e Tucídides, faziam da oralidade sua ferramenta e fonte, no século XIX firmou-se a exigência de uma história ancorada em provas documentais. Mas, desde ao menos o final da década de 1920, essa exigência tem sido contestada. Aquela história positivista, linear e atenta quase exclusivamente a personagens públicas da vida política, preocupada com uma verdade única e comprovada, levada ao palco por Leopold von Ranke, não encontra mais espaço na historiografia contemporânea.

Nos anos 1920, Lucian Febvre e Marc Bloch, entusiasmados com as novidades da antropologia, anunciaram uma perspectiva historiográfica informada por métodos e conceitualizações emprestados de outros campos disciplinares: a Escola dos Annales. A proposta desse movimento era de colaboração interdisciplinar, o que nos faz notar que as fronteiras disciplinares não são assim tão policiadas como a lógica departamental universitária às vezes nos faz pensar. Nos anos 1960, uma geração de praticantes da história, afinada com a perspectiva dos Annales, agregou amplamente os estudos de outras disciplinas em seus trabalhos: Michele Perrot, Jacques Revel, Jacques Le Goff, Arlete Farge, Philippe Ariès, Jean Delumeau, George Duby (que lia Marcel Mauss e Malinowski), etc. Essa geração abriu as possibilidades daquilo que se convencionou chamar "viragem antropológica", perspectiva historiográfica que se colocava contra o determinismo e dava ênfase às construções culturais, incorporando teorias de autoras de outras áreas disciplinares, como Michel de Certeau, Pierre Bourdieu, Roger Chartier, Michel Foucault (teorias da sujeita), Paul Ricoeur (todas as obras são narrativas), Pierre Nora (história da memória), etc. Houve quem chamasse seus trabalhos de "antropologia histórica" ou "etno-história". Afinal, a antropologia, a partir de sua rica tradição etnográfica, forneceu às praticantes da história novos métodos e técnicas de trabalho, assim como conceitos, temáticas e problemas de estudo.

Ao passo que os Annales se anunciaram como uma escola historiográfica de abordagem interdisciplinar, acabaram também expandindo teorias e conceitos da história para diversas outras áreas, como, por exemplo, a noção de duração, a ideia de que não há memória sem temporalidade e o próprio conceito de historicidade. Nesse contexto de tráfego de teorias, praticantes da história acabaram formulando a possibilidade de pensar novas fontes para a história para além de fontes documentais/escritas, abrindo espaço para o retorno da oralidade e da narrativa. A questão da oralidade, portanto, 
ultrapassou o campo específico da antropologia e é agora objeto de outras disciplinas, como é o caso da história oral.

A história oral é um campo que se propôs originalmente como interdisciplinar, pois articula análises da oralidade amparada nos arcabouços teóricos da história, da literatura, da antropologia, da linguística, da psicanálise. A partir da técnica da entrevista, a história oral se configurou como metodologia propositora de um novo entendimento acerca da memória como fonte histórica, mostrou as diversas temporalidades que destroem a linha do tempo política, colocou em evidência o tempo subjetivo. Não se trata simplesmente da transcrição da entrevista gravada, nem de uma pretensão exclusiva de formar arquivos orais, mas de uma produção de conhecimento histórico com todos os cuidados dispensados a qualquer outra fonte.

A ideia central no campo da história oral é dotar a memória de historicidade, mostrar que ela é possível num dado contexto em que é provocada. Há já algum tempo que a proposta de que a memória poderia revelar ou desvelar o real foi abandonada, pois uma análise da memória implica considerar que as memórias são interpretações da experiência vivida, são datadas e podem ser historicizadas. Há quem tenha falado em "história participativa", talvez em alusão ao método antropológico da "observação participante", pois se admite amplamente que a significação da memória é de certa forma provocada pela pesquisadora que pergunta. Alinhado a essa noção, Alessandro Portelli propõe que entendamos o texto resultante do encontro entre perguntadora e perguntada como um trabalho em coautoria (Portelli, 2010). Um outro argumento que evidencia o fato de que a história oral é muito mais que uma decisão técnica ou um procedimento é que ela estabelece uma relação original entre a historiadora e a sujeita da história, demonstrando, e de maneira muito convincente, que o objeto histórico é sempre resultado de uma elaboração por parte da historiadora: a história é construção. Portanto, não se trata, nesse campo, de uma renúncia às exigências teóricas, visto que há rigor teórico e metodológico na história oral.

Se a história oral se constituiu por confluência multidisciplinar, isso foi possível dentro de uma tradição historiográfica que já vinha se desenvolvendo no debate com outras disciplinas. Há muito que a historiografia contempla questões culturais e simbólicas e partilha interesses sobre a formação de identidades coletivas nos grupos humanos, temáticas essas originais dos estudos antropológicos. 
E se a memória é objeto original da história, a antropologia tem experimentado e contribuído para os debates sobre essa categoria. Apropriando e revendo trabalhos de autoras como o sociólogo Maurice Halbwachs (memória coletiva), do filósofo Henri-Louis Bergson, do filósofo Gaston Bachelard (conceito de duração), do filósofo Paul Ricoeur (experiências são mediatizadas por sistemas simbólicos), Gilbert Duran (memória sob o domínio do fantástico), a antropologia tem tomado para si um lugar na discussão acerca da memória e do tratamento dado a ela. Cornelia Eckert e Ana Luiza Carvalho Rocha têm sugerido uma etnografia da lembrança da duração, concebendo o tempo como uma série de rupturas e a memória como conhecimento de si e do mundo a partir do trabalho de recordar narrado pelas sujeitas. A memória, dizem as autoras, é composição do passado e do futuro e os trabalhos da memória são fabricações intelectuais. Um estudo das memórias, portanto, nos evidencia a multiplicidade de experiências de indivíduas e grupos (Eckert; Rocha, 2000).

Um outro campo de convergência da história e da antropologia se configura nos estudos biográficos. Aqui, a antropologia deixa bastante evidente a incorporação de uma variedade de conceitos historiográficos no exercício etnográfico e na definição dos objetos de pesquisa, aprofundando suas relações com a história.

Junto a essas discussões, e em jogo com elas, temos lido críticas antiessencialistas no discurso acadêmico, bem como a desconstrução das perspectivas identitárias em várias áreas disciplinares. Stuart Hall, inspirado em Derrida, coloca a identidade como um conceito "sob rasura". Este autor considera a identidade categoria central para pensar a agência e a política, mas prefere incluir em suas análises a noção de identificação, que toma como um processo de articulação, de suturação, de sobredeterminação, mas nunca uma subsunção ou ajuste completo, nunca uma totalidade, pois que envolve um trabalho discursivo de marcação de fronteiras simbólicas e de produção de efeitos de fronteiras (Hall, 2003). Se os processos de identificação requerem o exterior que os constituem, ao interpretar as narrativas estamos dando significados ao modo como uma indivídua singular interpreta e joga com os códigos culturais para produzir-se a si mesma. Joan Scott argumenta que a experiência narrada já é uma interpretação e precisa de interpretação, e o que se conta como experiência não é nem autoevidente, nem definido, mas sempre contestável e político (Scott, 1999). A partir dessas considerações, compreendemos que ao analisar a memória da experiência, não há como encontrar uma narrativa 
sobre a sociedade, o público, o político, e outra sobre a indivídua, o privado, o psicológico, porque a experiência se dá na imbricação de todos esses âmbitos e é na experiência que se constituem as sujeitas. Esse entendimento coloca necessariamente em debate o fato de que às mulheres está reservado um lugar social específico, que lhes permite experimentar uma existência distinta da dos homens e que lhes constitui como "diferença" em relação ao sujeito masculino. Tais teorizações da sujeita trouxeram ao debate novas problemáticas acerca do tratamento dado à memória.

Esse debate está obviamente informado pelas epistemologias feministas, que, a partir de uma diversidade de posições, exploraram ambiguidades nos conceitos fundamentais da filosofia acerca do sujeito universal, autônomo, racional (e masculino) (e branco). A força subversiva do feminismo, se entendido como sintoma das contradições do individualismo liberal (Scott, 2002), está na própria reformulação da ideia de individualidade. Nos anos 1960 e 1970 , as práticas discursivas feministas, que convencionamos chamar de "feminismos de segunda onda", 5 se ocuparam do direito ao corpo e ao prazer, de pensar uma cultura feminina específica, uma psicologia, uma memória, uma subjetividade feminina. Essa discursividade deu lugar para a constituição do conceito de patriarcado, perspectiva que, apesar do potencial mobilizador, acabou por reforçar a ideia de uma identidade universal de ser mulher, pois que se reconhecia a opressão fundada nas diferenças sexuais. Com especial tom marxista, porque manifesta aquela ideia de que há oprimidas e opressoras, um tanto simplisticamente articuladas como categorias estanques e polarizadas, o arcabouço teórico que produziu o patriarcado como alvo do ataque feminista acabou por reforçar noções biologizantes sobre a sexualidade.

Nos anos 1980, a categoria gênero foi elaborada, dentro do que chamamos "feminismos de terceira onda", como uma ferramenta para analisar a construção social e cultural daquilo que se entende por feminino e masculino, mostrando formas pelas quais as sujeitas se constituem e são constituídas nas tramas das relações de poder. Gênero foi a virada epistemológica nos estudos feministas e nos trouxe a possibilidade de pensar uma memória educada para determinados papéis, uma memória culturalmente formatada pelos sentidos do feminino e do masculino, e preterir a ideia de uma memória feminina exclusiva ou essencial.

5 Convencionamos chamar "feminismos de primeira onda" os movimentos sufragistas. 
Ainda hoje, muitos estudos se apropriam do gênero apenas como uma variável da composição do grupo pesquisado entendendo-o como um sinônimo de mulheres, deixando de fazer uso do caráter explicativo dessa categoria de análise. Foi com o gênero, elaborado concomitantemente aos estudos coloniais, que o feminismo acadêmico foi legitimado e integrou-se à comunidade científica, passando a irrigar, junto a outros movimentos sociais, as ciências humanas. Apropriado por diferentes disciplinas, não há como negar a vocação política interdisciplinar dos estudos de gênero e há, também, que se reconhecer que esse é um campo propositor de conceitos. Mostrar que não há uma memória feminina essencial foi um posicionamento engajado com a discussão sobre o próprio conceito de memória, sobre aquilo que se considera memória histórica, memória válida, constituindo, pois, um novo lugar nas disputas pela memória. O gênero, produção do arcabouço teórico feminista, mostrou, fazendo uso de métodos científicos exigidos pela comunidade acadêmica, que os trabalhos dessa própria comunidade estavam limitados a uma perspectiva masculinista e heteronormativa. Françoise Thébaud, ao abordar as transformações provocadas pelo uso do gênero na pesquisa acadêmica, mostra como a disciplina história foi, por muito tempo, considerada masculina. Ela nos explica como novos projetos de rememoração ambicionados na perspectiva de dar visibilidade às experiências passadas das mulheres fizeram mais que explorar temáticas consideradas femininas, como a maternidade, o aborto, a prostituição, o corpo, etc.; pois além de abrir novos campos de investigação, os estudos feministas reviraram a própria noção de problematização histórica (Thébaud, 2009). A noção de que a memória é atravessada pelo gênero traz a essa categoria importância central nas discussões sobre memórias travadas nas ciências humanas.

O interesse pela oralidade, revivido pela antropologia e reapropriado pela história, trouxe, portanto, novas possibilidades de explorarmos experiências de pessoas comuns e acontecimentos da vida privada. Se às mulheres foi, por muito tempo, reservado o espaço privado, o lugar do silêncio e o anonimato próprio de quem transita por chãos de fábrica, cozinhas e alcovas, também as experiências dos homens comuns ficaram invisibilizadas no discurso historiográfico. A fonte oral se apresenta, portanto, duplamente armada: nos oferece a chance de transitar por domínios entendidos como privados, particulares, considerados irrelevantes para a esfera pública e, mais ainda, nos permite visitar percursos de rememoração da experiência de constituição da sujeita por ela mesma. 
Hoje, é possível pensar como a sujeita se constitui na experiência, como somos efeito e produto de processos de subjetivação e não um dado em essência. Estamos, afinal, considerando a narrativa oral como um processo e reconhecemos que estamos implicadas no resultado da entrevista, pois contribuímos com sua criação por meio de nossa presença, de nossas perguntas, de nossas reações. Nós, perguntadora e perguntada, nos observamos durante um encontro mediado por um gravador e um caderno de anotações. Não é nossa intenção recolher memórias como se elas fossem dadas, já prontas à nossa espera, afinal não há fonte que preexista à pesquisa. Tampouco esperamos nos colocar numa posição de quem chega para ouvir um testemunho, ou um depoimento, ou para arrancar uma verdade da pessoa que nos fala. Isso combina mais com as intençóes do procedimento judiciário de autenticação da verdade. No entanto, reconhecemos que a entrevista é uma relação de poder: a pesquisadora é quem diz o que as palavras significam, descreve as expressóes daquela que lhe fala, seleciona o que é fonte e o que não é, decide quais trechos serão descartados e quais perguntas devem ser perguntadas. Mas, se mesmo a interpretação é parte de uma relação de poder, aquela para a qual dirigimos nossas perguntas pode recusar-se a responder e pode, ainda, brincar com nossas pretensões científicas. Mesmo assim, é a pesquisadora quem edita o texto e o organiza como uma verdade válida. Mas não sentimos que seja nossa obrigação transformar a transcrição da entrevista em um documento acabado, assim como não temos intenção de escrever algo que pareça um romance policial ou um relatório do que vemos e escutamos. Tampouco é nosso trabalho fazer uma espécie de psicanálise circunstancial. O que podemos fazer é procurar, nas nossas fontes, formas de produção de subjetividade; interpretar o que está sendo dito considerando que aquilo pôde ser dito dentro de um contexto criado por nós através da proposição da entrevista; analisar o texto sabendo que somos também responsáveis pela produção e significação daquela memória. Se rememorar é um processo, nosso trabalho é procurar nas memórias da experiência como a pessoa que nos fala joga com a cultura e produz a si própria na relação com a Outra, tornando dizíveis processos de constituição de si. Não se trata de uma retirada de informações, mas de interpretar como a pessoa que nos fala reconstrói a própria subjetividade, como percebe a si própria e como percebe o olhar da Outra, como se formula a partir de identificações, como ela entende o modo como se tornou o que é.

A antropologia se estabeleceu como disciplina com a proposta de investigar o homem (e, neste caso, não podemos flexionar o gênero) de outras 
culturas propugnada pela expectativa de um olhar neutro, que vê de fora. Novos paradigmas disciplinares têm nos feito abandonar a ideia de neutralidade, de um objetivismo racional, de um conhecimento essencial a ser alcançado, de informações puras prontas para serem recolhidas. Dificilmente poderíamos sustentar, hoje, que a pesquisadora bem treinada e promissora é aquela que não compartilha significados culturais com o grupo em estudo mantendo um distanciamento total do objeto de pesquisa. Afinal, trata-se de textualizar uma cultura sem intenção (pois que estamos conscientes da impossibilidade) de alcançar uma interpretação objetiva/objetivista. Também no campo da história se abriram possibilidades inusitadas. $\mathrm{O}$ relativo sucesso daquilo que se convencionou chamar história do tempo presente, em jogo com as metodologias da história oral, se apresenta exemplarmente como um anúncio de que nós abandonamos a ideia de que para se fazer história é preciso olhar de longe (a fim de garantir a tão desejada objetividade).

Com isso não queremos nem mesmo insinuar que nosso trabalho se assemelhe ao trabalho daquelas que se dedicam às artes literárias, ofício esse para seres de criatividade extraordinária, pois que é desprendido de regras cognitivas severas como as que estamos nós submetidas dentro das malhas de saber acadêmico. No entanto, estamos certas de que o que gostamos de fazer é observar, ouvir e contar. E se, como ensina Ruth Cardoso (1988), observar é contar, descrever e situar fatos, construindo cadeias de significação, talvez valha a pena levar em consideração a advertência de Alessandro Portelli (2010) de que todas e todos nós falamos em prosa.

\section{Referências}

CARDOSO, R. Aventuras de antropólogos em campo ou como escapar das armadilhas do método. In: CARDOSO, R. A aventura antropológica: teoria e pesquisa. 2. ed. Rio de Janeiro: Paz e Terra, 1988. p. 95-105.

DELEUZE, G. Conversações. Trad. Peter Pelbart. Rio de Janeiro: Ed. 34, 1992.

ECKERT, C.; ROCHA, A. L. C. Imagens do tempo nos meandros da memória: por uma etnografia da duração. Iluminuras, Porto Alegre, v. 1, n. 1, p. 2-14, 2000.

FOUCAULT, M. O nascimento da clínica. 2. ed. Rio de Janeiro: Forense-Universitária, 1980.

. História da sexualidade 2: o uso dos prazeres. Trad. Maria Thereza da Costa Albuquerque e J. A. Guilhon Albuquerque. Rio de Janeiro: Graal, 1984. 
. História da sexualidade 3: o cuidado de si. Trad. Maria Thereza da Costa Albuquerque e J. A. Guilhon Albuquerque. Rio de Janeiro: Graal, 1985.

. História da sexualidade 1: a vontade de saber. Trad. Maria Thereza da Costa Albuquerque e J. A. Guilhon Albuquerque. Rio de Janeiro: Graal, 1988.

. A arqueologia do saber. Rio de Janeiro: Forense Universitária, 1986a.

$1986 \mathrm{~b}$.

Vigiar e punir: nascimento da prisão. Trad. Ligia Vassalo. 4. ed. Petrópolis: Vozes, . As palavras e as coisas. São Paulo: Martins Fontes, 1995.

1996.

. A ordem do discurso. Trad. de Laura Fraga de Almeida Sampaio. São Paulo: Loyola, . Sexo, poder e individuo: entrevistas selecionadas. Trad. Jason de Lima e Davi de Souza. Desterro: Nefelibata, 2003.

GEERTZ, C. Works and lives: the anthropologist as author. Stanford: Stanford University, 1988.

GEERTZ, C. A interpretação das culturas. Rio de Janeiro: LTC, 1989.

HALL, S. Quem precisa de identidade? In: SILVA, T. T. da. Identidade e diferença. 2. ed. Petrópolis: Vozes, 2003. p. 103-133.

OLIVEIRA, R. C. de. A antropologia e a crise dos modelos explicativos. Estudos Avançados, São Paulo, v. 25, n. 9, p. 213-228, 1995. Disponível em: <http://www.scielo.br/pdf/ea/ v9n25/v9n25a17.pdf>. Acesso em: 16 fev. 2012.

PORTELLI, A. Ensaios de história oral. São Paulo: Letra e Voz, 2010.

SCOTT, J. W. Experiência. In: SILVA, A. L. da; LAGO, M. C. de S., RAMOS, T. R. O. (Org.). Falas de gênero: Teorias, análises e leituras. Florianópolis: Mulheres, 1999. p. 21-55.

. A cidadã paradoxal: as feministas francesas e os direitos do homem. Florianópolis: Mulheres, 2002.

THÉBAUD, F. Políticas de gênero nas ciências de gênero: o exemplo da disciplina histórica na França. Espaço Plural: história das mulheres e das relações de gênero, Universidade Estadual do Oeste do Paraná, n. 21, p. 33-42, 2009.

VEYNE, P. Como se escreve a História / Foucault revoluciona a história. Trad. Alda Baltar \& Maria Auxiliadora Kneipp. Brasília: Ed. UnB, 1982. 
Resumo: Memória e identidade são categorias operacionalizadas em reflexões de diferentes campos disciplinares. Elaboramos um percurso das disciplinas antropologia e história para mostrar como elas foram, no século XX, se configurando em torno de questões epistemológicas comuns. Se a entrevista é uma técnica de produção de fonte nas duas disciplinas, escrevemos na perspectiva de produzir uma solução, ainda que circunstancial, para tratar as fontes orais informadas por esses dois campos de saber. Tomamos a memória como lugar de produção de subjetividades e mostramos como a categoria gênero, elaborada dentro dos estudos feministas, propiciou novas teorias da sujeita e trouxe ao debate novas problemáticas acerca do tratamento dado à memória.

Palavras-chave: memória, antropologia, história, gênero.

\section{Approaching memories in History and Anthropology}

Abstract: Memory and identity are categories operationalized in reflections of various disciplinary fields. We briefly reviewed the anthropological and historical approaches on memories during the twentieth century in order to show how these disciplines have developed around common epistemological issues. If the interview is a technique for producing research sources in both disciplines, we wrote with the objective of producing a proposal, albeit circumstantial, to deal with oral sources informed by these two fields of knowledge. We take memories as a place of production of subjectivity and show how the category of gender, developed within the feminist studies, developed new theories of the subject and brought new issues to the debate about the treatment given to memory within Human Sciences.

Keywords: memories, anthropology, history, gender.

Recebido em 01/08/2012

Aprovado em 24/10/2012 